\title{
Reconceptualising Government in the New E-Ra
}

\author{
Ailsa Kolsaker ${ }^{1}$ and Liz Lee-Kelley ${ }^{2}$ \\ ${ }^{1}$ School of Management, University of Surrey, GU2 7XH Guildford, Surrey, UK \\ a.kolsakerasemsserver3. sems. surrey.ac.uk \\ ${ }^{2}$ School of Management, University of Surrey, GU2 7XH Guildford, Surrey, UK \\ L. Lee-Kelley@surrey.ac.uk
}

\begin{abstract}
The UK e-government initiative is strongly positivist and rationalist, built upon a competency model of efficiency which embraces only explicit knowledge and measurable outcomes. As a result e-government provision is being driven not by citizens' needs but by a techno-centric, bureaucratic culture which is at odds with successful delivery and adoption. We suggest that government must refocus from the current rationalist approach to a broader, cross-boundary, institutionalist discourse which acknowledges socio-technical, cultural complexities at the regional, national and European level. Challenging though this may be, if Web technology is to be exploited fully and citizens' needs fulfilled, we conclude that government must acknowledge and seek to harness both tacit and phenomenological knowledge, requiring a fundamental rethink of the form of knowledge being collected, codified, transferred and applied.
\end{abstract}

\section{Introduction}

According to Deloitte Research (2002:1) governments are determined to leverage all of the advantages of the new economy in anticipation that the "era of e-government that is to say transformative government - is here to stay". However, the extent of change is open to interpretation; for some e-government may represent a fundamental transformation of governance, whilst for other it may be incremental and start simply with enhanced services and delivery. Thus, whilst e-government has been 'sold' as a tool to service and support both the citizenry and businesses, definitions and aspirations within these two realms tend to be correspondingly broad, with significant variation in both scope and operationalisation.

In the UK, the Labour Administration not only regards e-government as a new service platform targeted at the needs of the citizens, but also one that allows central government to collect, collate and mine population data economically. For the first time, communicating to and building knowledge about the populace may be done relatively easily, cheaply and quickly. Just as 'knowledge' in commerce is seen as an intangible asset with which to build competitive advantage, in politics its potential as a defence against policy opposition has also been recognised.

The white paper 'Modernising Government' describes e-government as:

"....joined up working between different parts of the government and providing new, efficient and convenient ways for citizens and business to communicate with government and receive services." 
The tone and flavour of the white paper points to a strongly positivist discourse, presupposing knowledge to be explicit, rationally- based, objective, highly structured, relatively static and without prejudice or favouritism. Within such a discourse both knowledge structures and processes are clearly delineated and heavily rationalised within a technological framework. Thus, an additional presupposition is that this explicit knowledge may be harvested, fitted together, jigsaw-like, according to a predetermined design and facilitated by technology to produce a holistic 'joined up', easily accessible platform.

This institutionalist vision and the consequent policies and rules of e-government are driven from the highest levels; however the delivery is determined by public sector agencies, government departments and local government. Central government's success or failure is therefore dependent on the latter's willingness and ability to engage the public as envisioned. Although Zhou (2001) argues that conflicts between different departments and agencies can only be coordinated at the highest level of government, this ignores recent trends towards greater agent/client integration where users participate actively in a cumulative feedback loop.

In addition, the increasing assumption of the 'right to know' in modern $21^{\text {st }}$ century society means further pressure on instantaneous information dissemination. The need for government to use advancing technologies for 'real time' communication to the public is aptly summarised by Benn Wegg-Prosser, a former Labour government spin doctor: "The advance in communications methods means you can't really keep such briefings private in the way you used to - mobiles, pagers and the Internet have seen to that." A report by traffic measurement company Hitwise that the official Hutton Inquiry website, which gives information on the death of UK scientist, Dr. David Kelley, was the most visited political website in the UK in July 2003 is a testimony of the public's thirst for knowledge. Yet, government department websites are generally far less sophisticated than corporate websites (BBC News, 3 Sept 2003) and are a long way from maximising the potential for two-way, interactive communications with the public.

Hence, from the citizens' perspective, it might be conceived that whilst egovernment services ostensibly fulfil their needs, in fact provision may not be sufficiently timely, adequate, accessible or interactive enough to achieve this in practice. To Muid's (1992:125) far-sighted query, "Are citizens ready to have their governments led by technological innovation?" we add the caution of a lack of synchronisation between vision and delivery.

In this paper we adopt a socially-based approach to question whether assumptions underpinning current e-government communication initiatives are at odds with the historically embedded organisational knowledge and practices of public sector officials and servants, and whether the existing mechanisms for interface, coordination and control are congruent with the rules of e-governance and provision of e-services.

\section{E-government for Knowledge Management: 'Spin' or 'Reality'?}

Government policies have direct and indirect social as well as economic consequences. For example, Thatcherite free-market philosophy dominated the 1980s and resulted in driving a wedge through the sense of community and greater good in 
preference of the so-called 'me-first' society. In the 1990s, under Major, the pendulum began to swing towards a competency-based view of health, education and training needs with increased emphasis upon public sector transparency and accountability, including the introduction of 'citizens'charters' as service quality measures. While sceptics naturally decry such efforts as superficial, the 'reality' of the success of such well-meant initiatives is difficult to construct from officially recorded outcomes, being dependent upon relative perspectives.

With the commercialisation of the Internet, Holmes (2001) saw its potential to extend the competency model of efficiency and effectiveness by enabling streamlining of processes and lowering costs (less paper, printing, mailing, personnel etc.). He also saw it as an opportunity for the UK central publicity machine to market e-government as a citizen-centric, empowering mechanism which offers enhanced choice, access, inclusion and quality of information. Each of these factors would require significant resources and effort to instigate and maintain - presumably emerging from efficiency savings overall. Another publicised reason for central government's push for e-government is the belief that it is an economic way to support and encourage business development. Through real-time provision government can help local businesses gain competitive advantage by providing data and information to aid decision-making. At the macro level other drivers of egovernment include creating awareness and raising the national profile of a country (e.g. New Zealand and Australia) and for smaller countries to compete in the global economy (e.g. Singapore, Malaysia). Therefore, given the popularity of egovernments on political agendas around the globe, it might be viewed as a channel for keeping UK Plc and the Labour government on the world map. Certainly UK Prime Minister, Tony Blair, was quoted as saying "If you don't see the Internet as an opportunity, it will be a threat" (Financial Times, 1999).

Against this utopian view are voices asserting wider social exclusion and divide between those who have access to the Internet and those who do not or cannot. One such report is that by Continental Research (2002) which identified the existence of the 'digital divide' between the 'e-literate' and those lacking access and/or confidence. Lee-Kelley and James' (2003) study confirms the earlier report and also highlights language as another barrier. With sections of society excluded from electronically-based communications, this has implications both for the effectiveness of such communications and the type, calibre and function of the intelligence collected.

Furthermore, the Society of Information Management Technology (SOCITM) (2003) has criticised the UK white paper, particularly its prescribed date of 2005, arguing that authorities which are already struggling to meet other government initiatives will fall further behind. This augments Sewards' (1998) earlier report on delivery barrier issues which included short-termism, training public servants, seeking consistency across multiple jurisdictions and matching services to demand. This begs the question of whether the government's vision of efficient, convenient communications will ever be much more than 'spin'.

To make sense of this we draw upon knowledge-based organisational theory which identifies the essence of organisational capability as the integration and creation of knowledge. Following Penrose (1959, in Lam, 2000) knowledge-based theory regards the organisation itself as a body of knowledge residing in its structures of coordination. According to Lam (2000) from this base observed differences in organisational principles between organisations reflect their differing knowledge 
bases and capabilities. Despite on-going, radical reform, the UK public sector remains functionally structured, bureaucratically uncommunicative and increasingly process driven. Thus, if organisations are to be conceptualised as bodies of knowledge residing within structures of co-ordination and if capability is to be measured in terms of knowledge integration and creation, then a generous definition would be that public sector capability is 'bounded.'

Disaggregating spin from reality also requires consideration of the taxonomic distinction of knowledge along the two dimensions of degree of aggregation and degree of articulation (Spender, 1996; Nonake and Takeuchi, 1995; Lam, 2000). Whereas the prevailing conceptualisation, organisation and delivery of e-government presupposes knowledge to be explicit and therefore easily aggregated, structured and stored, the reality is much more complex. Following Polanyi's distinction, even if the stored knowledge is explicit, the nature of e-government delivery requires some degree of tacit knowledge, personal know-how, skills and motivations in order to manipulate the technology and access the stored knowledge. Additionally, as Nonaka (1994, in Lam, 2000) points out, the individual's involvement in the context is crucial in determining the generation and accumulation of explicit knowledge, thus supporting the broad consensus that the distinction between explicit and tacit knowledge is artificial and that in practice the two are mutually reinforcing and dependent. The challenge for government is to balance the desire to provide extensive knowledge management capabilities through the technological platform, which may never be exploited fully, with a recognition that the design of organisational structures, processes and procedures should consciously and deliberately spread tacit knowledge across departmental boundaries. This is the essence of knowledge articulation, which we argue is a pre-requisite for successful knowledge management. Lubit (2001) identifies the limited efficacy of most knowledge management efforts as being due to an overwhelming focus on creating the means to capture and store information and improve communication at the cost of persuading people to use systems effectively.

Hence, there appear to be inconsistencies between the prevailing highly structured, rationalist approach to e-government and the actual delivery of knowledge through eservices. Provision appears to be driven by presuppositions which accommodate the prevailing techno-centric context and bureaucratic culture rather than by a determination to respond to citizens' requirements. Evidence suggests that internal structures and processes, behavioural norms, managerial practices and outcome measures collude to reinforce historically embedded practices which do not fit comfortably with the new communications-based electronic era. A scan of 'ukonline' and most of the government local authorities, boroughs, health authorities and other agencies/departments reveals their websites at varying stages of 'e-readiness'. Few are fully integrated and interactive and many are in fact 'shells' with minimal information and navigability. Indeed, one example indicating the resistance of government departments to change (or if one were charitable, it could be the result of resource constraints), is a word-processed letter sent by post, in reply to various email chasers by a citizen's inquiry about his application for council tax exemption for an unoccupied flat: apparently, the official target for reply to any correspondence (including emails) is 10 working days!

It is hardly surprising therefore, that public cynicism prevails as to the 'true' motives of government, which they see as couched in neo-liberal managerial tones, engineered from the top with little input from the grass-roots. It may be that central 
government needs to move away from regimenting assumed knowledge to permit greater local autonomy at departmental/agency level. This might facilitate the incorporation of local knowledge as well as real communication between provider and user, thus potentially neutralising the biases of those producing e-government information. Perhaps a deeper understanding of both tacit and phenomenological knowledge is required in order to optimise adoption and maximise the value of egovernment services to citizens - though this in itself may be an anathema to the agents actively involved in the production and management of e-service provision. However, of note is the question: Rose tinted glasses apart, how aware is central government of the structural limitations of their systems and resistant behaviour of their officials to offering a truly citizen-centric public-interface? To understand the veracity of the divergence between vision and delivery, we propose that the answer might lie in the 'biases and purposes' of the philosophy of knowledge management within public management theory.

\section{3 'Biases and Purposes'}

The government's approach draws heavily upon what Bourdieu defines as theoretical knowledge, in other words the construction of the objective relations that structure practice and the representations of practice. According to Acciaioli (1981) theoretical knowledge attempts to delineate structures existing prior to persons, structures that make possible the knowledge and primary experience of those persons. Conceptualising explicit knowledge in these terms fits comfortably with the dominant managerial model of governance, characterised by the economic rationalism of human capital theory in which individuals are both willing to and capable of maximising their own value. This discourse fashions the structuring and presentation of knowledge such that it facilitates economic-rational man's decision-making.

Similarly, the dominant managerial discourse dictates organisational forms which promote efficiency and effectiveness, productivity and profitability. Thus, the government's drive towards e-provision is essentially prescribed and imposed from the centre. According to Armistead and Meakins (2002) such an approach is usually accompanied by formal structures and bureaucratic systems to capture, store and distribute knowledge, with attempts to measure the value of knowledge through formal systems. Within such a context there is a strong emphasis upon measurable outcomes and the capability of technology within an increasingly competitive culture. According to Nielsen and Ciabuschi (2003), however, knowledge sharing decreases as the level of competition within an organisation increases. Thus, within a bureaucratic regime there is an unspoken motivation not to share knowledge since, as identified by Weber (1978) the power of the bureaucrat rests upon two types of knowledge; 'technical know-how' and 'official information'. As the former may be shared by many, an individual's 'competitive advantage' may lie in the latter, particularly if gleaned informally. Thus, organisational culture is a key determinant of knowledge-sharing and communication. Damodaran and Olphert (2000) posit that an overly techno-centric approach may fail to produce a culture and context which nurtures organisational learning. Somewhat paradoxically, they identify such an approach as the most common cause of the failure of knowledge management systems. Damodaran and Olphert (2000) espouse instead a socio-technical system 
which has as its objective the management and sharing of knowledge to support the achievement of organisational goals. This supports Lam's (2000) view, drawing upon Boisot (1995) and Lam (1996; 1997), that the extent to which tacit knowledge constitutes the knowledge base of the organisation and how it is formed and used are powerfully shaped by the broader institutional context, and, further, that an interactive relationship exists between the dominant forms of knowledge and organisational form (Lam, 2000.)

Considering the wider institutional perspective we may draw upon Foucault's conception of institutions from a technological perspective that is as practices that put in play certain assumptions and objectives concerning the selves that inhabit them (Foucault, 1977 in Rose 1992.) This may explain why despite decades of substantive and ongoing reform, a number of civil service departments and public agencies might still be described as 'sclerotic, unresponsive and inefficient government, entrapped by iron triangles, unionism, and overbearing civil service' (Dobel, 2001:167) - though Dobel was referring to the 1970s and early 1980s. Despite government rhetoric, crossboundary integration of departmental knowledge has fallen well short of expectations. Communication is woeful inadequate; multiple points of contact continue to exist with minimal integration or knowledge-sharing, or even information being in a sharable format. E-government services may be failing to reach their potential in terms of usefulness and usage because the citizen-centric e-government rhetoric is at odds not only with the prevailing techno-centricity, but also the established and powerful socio-cultural dynamics within and across departmental boundaries.

Additionally, within bureaucratic departments historically embedded institutional practices are likely to distort further the pursuit of e-government objectives. These may encompass individual as well as departmental objectives and priorities as well as decision-making routines, the format and style of operational processes etc. Thus, the sought knowledge synergies may remain illusionary because, according to Nielsen and Ciabuschi (2003) more specialised, focused initiatives are easier to measure - and have the advantage of already being in existence. Such practices serve to reinforce existing norms and priorities and, far from being reshaped by the e-government platform, actually fashion the knowledge and technology in order to facilitate integration into the existing context. Grote and Baitsch (1991) observed similar patterns with the introduction of I.T., concluding that a knowledge sharing culture must either already exist or be developed in parallel with the introduction of technology. This is supported by Mohrman et al (2002) who identify knowledge sharing as one of four identifiable work behaviours which impact upon the effectiveness of knowledge generation, leveraging and application (the other three being: focusing on system performance rather than narrow technical outcomes; following systematic processes, and trying new approaches.)

Integration can not be achieved unless departments are willing to cooperate, yet in practice conflicts arise at both departmental and personal levels over the sharing, management and ownership of knowledge. Husted and Michailova (2002) posit that individuals are inherently hostile to knowledge sharing. This may be due to feelings of vulnerability as it might be thought that the essentially process-oriented tacit knowledge held by civil servants could more easily be replicated than other forms of expert knowledge. Nielsen and Ciabuschi (2003) identify this as 'loss of personal market value' in other words the fear of becoming superfluous if personal or tacit knowledge is shared with others. It could also be that if knowledge transfer is not an integral part of operational processes there is unlikely to be much support for 
dissemination for its own sake, particularly as, as identified by Nielsen and Ciabuschi, (2003), the sharing of knowledge takes time, which people in general do not have. Effective forms of knowledge management focus need to be action focused - if not, they will not be considered relevant and very possibly ignored. Unfortunately, according to Lubit (2001), people are not only hesitant to share what knowledge they have, but equally hesitant to use the knowledge of others - the 'not invented here syndrome.' This can only be overcome by proactive management which, having identified the value residing in the knowledge, be it explicit or tacit, specifies the sharing and application of knowledge as an expected, rather than a desired behaviour.

Though management may be extremely influential, success remains elusive. Individual managers may be unable to switch from their established mechanisms of coordination and control to those involving a people/technology mix. This may be exacerbated by the problem identified by Armistead and Meakin (2002) of technological expertise being located with I.S. experts and users performing suboptimally through skill deficiencies. Difficulties in judging the relative effectiveness of the employee and the technology therefore may discourage managers from playing a critical role not only in capturing appropriate and relevant knowledge but working towards the creation of a knowledge culture. Additionally, managers may simply be ill-equipped to codify knowledge, particularly if tacit in nature. Thus, in sum, uncertainty, lack of ownership and a degree of technophobia may all contribute to an overall lack of willingness and ability to integrate, impacting negatively upon egovernment provision and effectiveness.

\section{Conclusion}

The dominant inclination in modern society is the legitimacy of rationalised and logical forms of knowledge, which totally ignores other ways of doing and thinking about truth and reality (Garvey and Williamson, 2002). In the context of our present discussion, this tendency certainly appears to be exhibited by UK central government in their approach to e-government and knowledge management. This lack of understanding of the complexities of human logic coupled by inadequate investment, and systems and infrastructure limitations serve only to create a frustrating divide between an ambitious vision and an under-developed delivery.

In this paper, we have limited our discourse to the boundaries of the United Kingdom, however the global nature of the information super-highway is such that egovernment exchanges are very much part of the 'whole' knowledge creation phenomenon. It is crucial that future examinations of e-government vision and delivery should include accompanying cross-border issues. Instantaneous communications of world events (e.g. September 11, SARS and currently, the occupation of Iraq) and technology enabled shifts in working and leisure patterns, are important markers for changing informational relationships. There is also an increasing willingness towards greater cooperation between various law enforcement agencies. Ultimately this Europe-wide or even global policing would necessitate a revamp of localised government attitudes and competencies in favour of higher connectivity. Presumably, this logic would apply throughout the entire governmental structures. In the EU, individuals are no longer subject to all embracing, local 
sovereign laws and regulations - there now exists, a higher authority and power residing in Brussels! Through the Internet and the e-government vehicle (provided they are suitably well advanced in their 'transformation'), citizens can use the knowledge to make enlightened decisions of where to live and where to work to maximise income and quality of life. For businesses, e-government is cross-border government and there is a need to review their expectations of what these e-services and provisions can do to enhance or protect their competitiveness - indeed protecting them from whom.

In short, we conclude that the conceptualisation of knowledge, has moved from a small, regionalised ' $\mathrm{K}$ ' to a larger, more complex, ' $\mathrm{K}$ ', and its collection and collation, will need to be carefully understood, defined and crafted for informed government decisions and policies. Sir Isaac Newton's explanation of his success: 'If I have seen further, it's because I have stood on the shoulders of giants' is an apt reminder of the need for government to listen and learn from others.

\section{References}

1. Acciaioli, G.L. (1981) Knowing what you're doing: a review of Pierre Bourdieu's 'Outline of a Theory of Practice', Canberra Anthropology IV: 1, 1981, pp. 23 - 51

2. Armistead, C. and Meakins, M. (2002) Framework for Practising Knowledge Management, Long Range Planning, 35, 1, pp. 49 - 71

3. BBC News Online (2003) 'No. 10 briefings were outdated', UK edition, $3^{\text {rd }}$ September.

4. Boisot, M (1995) 'Information space: a framework for learning in organisations, institutions and culture', London and New York, Routledge in Lam, A (2000) 'Tacit knowledge, organizational learning and societal institutions: an integrated framework', Organization Studies, Vol. 21, No. 3, pp. 487-513

5. Continental Research (2002) 'Internet Report: Huge Gap in Internet Class/Age Divide must be addressed for the Government's ukonline Initiative to Succeed'. Available from: http://continentalresearch.com/reports/internet.htm

6. Damodaran, L. and Olphert, W. (2000) Barriers and facilitators to the use of knowledge management systems, Behaviour and Information Technology, 19, 6, pp. 405 - 413

7. Deloitte Research (2002) 'e-Government's Next Generation: Transforming the Government Enterprise through Customer Service.' Available from http://www.deloitte.com/dtt/research/0,2310,sid\%253D2228\%2526cid\%253D3362,00.html

8. Dobel J.P. (2001) Paradigms, Traditions and Keeping the Faith", Public Administration Review, Vol. 61, no. 2, pp.166 - 171

9. Garvey, B. and Williamson, B. (2002) Beyond Knowledge Management, Pearson Education, Harlow

10. Grote, G. and Baitsch, C. (1991) Reciprocal effects between organisational culture and the implementation of an office communication system: a case study, Behaviour and Information Technology, 10, pp. $207-218$

11. Holmes, D. (2001) 'eGov - eBusiness Strategies for Government' ( ${ }^{\text {st }}$ ed.) Nicholas Brealey Publishing, London.

12. Husted, K. and Snejina, M. (2002) 'Diagnosing and Fighting Knowledge-Sharing Hostility', Organizational Dynamics, Vol. 31, no. 1, pp. 60 - 74

13. Lam, A (1996) 'Engineers, management and work organization: a comparative analysis of engineers' work roles in British and Japanese electronics firms, Journal of Management Studies, Vol. 33, no. 2, pp. $183-212$ 
14. Lam, A (1997) 'Embedded firms, embedded knowledge: problems of collaboration and knowledge transfer in global cooperative ventures', Organization Studies, Vol. 18, no. 6, pp. $973-996$

15. Lam, A. (2000). 'Tacit knowledge, organizational learning and societal institutions: an integrated framework', Organization Studies, Vol. 21, No. 3, pp. 487-513.

16. Lee-Kelley, L. and James, T. (2003) 'e-Government and social exclusion', International Journal of Electronic Commerce in Organisations, Fall.

17. Lubit, R. (2001) 'Tacit Knowledge and Knowledge Mangement: the Keys to Sustainable Competitive Advantage', Organizational Dynamics, Vol. 29, no. 3, pp. 164 - 179

18. Mohrman, S. A., Finegold, D. and Klein, J.A. (2002) 'Designing the Knowledge Enterprise: Beyond Programs and Tools', Organizational Dynamics, Vol. 31, no. 2, pp. $134-151$

19. Muid, C. (1992). 'New public management and normalisation: a natural combination?' Public Policy and Administration, Winter, Vol. 7, No. 3, pp 75-79.

20. Nielsen, B.B. and Ciabuschi, F. (2003) Siemens ShareNet: Knowledge Management in Practice, Business Strategy Review, 14, 2, pp. 33 - 40

21. Nonaka, I. and Takeuchi, H (1995). 'The knowledge-creating company: how Japanese companies create the dynamics of innovation', Oxford Press, New York.

22. Penrose, E. (1959) 'The theory of the growth of the firm', New York, Wiley, in Lam, A. (2000). 'Tacit knowledge, organizational learning and societal institutions: an integrated framework', Organization Studies, Vol. 21, No. 3, pp. 487-513.

23. Rose, N. (1992) "Governing the Enterprising Self" in The Values of the Enterprise Culture - the Moral Debate by Heelas P. and Morris P. (editors), Routledge, London

24. Sewards, T. (1998) 'International government approaches to stimulating the update of new online services', Centre for Services Research on Communication and Information Technologies (CIRCIT), Melbourne.

25. Society of Information Management Technology (SOCITM) (2003). Available from: http://www.socitm.gov.uk/nr/egovindex/index.html

26. Spender, J.C. (1996) 'Competitive advantage from tacit knowledge?' in Moingeon, B. and Edmonson, A. (eds) 'Organizational learning and competitive advantage', Sage, London, pp. 56-73.

27. Weber, M. (1978) Economy and Society, Vols. 1 and 2 (edited by G. Roth and C. Wittich), Berkeley, Ca: University of California Press

28. Zhou, H. (2001). Global Perspectives on E-Government, UNDESA report, December. 